\title{
Research and Discussion on Network Instruction System of Light Chemical Equipment Course
} \author{
Heng Zhang
1, a , Zhe Wang
1, b Lan $^{2, e^{*}}$ \\ ${ }^{1}$ College of Chemical Engineering, Qingdao University of Science and Technology, Qingdao, \\ Shandong, China, \\ ${ }^{2}$ College of Environment and Safety Engineering, Qingdao University of Science and Technology, \\ Qingdao, Shandong, China \\ ahgzhang@sina.com, b1911187001@qq.com, "875526389@qq.com, dgaohongkun123@163.com, \\ lanhuixia@163.com
}

Keywords: Network teaching; Engineering education; Teaching method; Reform in education; Light chemical

\begin{abstract}
The web-based teaching of professional courses in colleges and universities has represented the tendency of development of the information age. Aimed at the core course of light engineering-light chemical equipment, the practice and exploration of network teaching is researched in this paper. A method of network teaching of professional courses in colleges and universities is proposed, and an example execution is carried out. Its advantages and disadvantages are summarized and it points out improvement of teaching measures and the direction of future development.
\end{abstract}

\section{Introduction}

Light chemical equipment is one of the core specialty courses of light chemical engineering in Qingdao University of Science and Technology, which mainly interprets a variety of specialized equipment involved in the light chemical industry.

Through the study of the course, students can familiarize themselves with the common problems of the equipment involved in the production process of the light engineering industry and the structure and working principle of the main typical equipment, clarify its performance and enable students to master the selection, usage and management of equipment, maintenance and improvement and other aspects of the basic knowledge [1].

Since 2006, the course has been using traditional classroom teaching methods, which teachers in the podium teaching, and students use textbooks in the classroom to learn. However, this kind of teaching method can not adapt to the OBE-oriented engineering education concept, can not fully mobilize the enthusiasm of students to learn, especially in the face of information technology-based modern educational technology and mobile network as the main information. The development trend of communication can not be used well, the interest of students' learning is declining and the teaching effect is not ideal. Therefore, it is necessary to carry out the fundamental teaching reform.

From 2016 onwards, our school gradually introduced a number of the company's network teaching platform, by comparison, we chose Superstar Erya network teaching platform as light chemical equipment courses network teaching practice platform. We expected to realize the reform of curriculum teaching method through the characteristics of its mobile learning, interaction and comprehensive process evaluation.

\section{Construction of Network Teaching}

Teaching Content. Teaching platform must first have teaching content. We first through a variety of input methods, nearly ten years of teaching lesson plans, teaching syllabus, after-school thinking questions, teaching electronic lesson plans and test questions and other input networks, 
constitute the basic teaching content. Of course, it is not simply input on the network indiscriminately, but through years of classroom teaching practice, the students have passed the selection and approval of content to be re-integrated to form a new network of teaching content. The basis of choice is to take full account of the characteristics of students in the network, such as time fragmentation, easy to watch on the mobile phone. In addition, it also offers a large number of learning materials support, including nearly a decade of journal articles, engineering video, and animation. The platform has a particular advantage, is able to fully quote superstar company's own online books, made hyperlinks, once students clicked, they can directly enter the superstar library to read the book, which greatly enriched the teaching content, so that the course of learning becomes more scalability.

Students Management. In this platform, teachers can join the students to learn, by entering the student ID, you can build a study class. It is a good orientation-directed for students by setting a reasonable evaluation system, which makes them are aware of the learning model of the course, and what should be done on the network to get higher scores and should not do to avoid wasting time, thus forming the network learning habits and learning methods.

Taking this course as an example, we set up the curriculum to make a reasonable evaluation of the development of students' knowledge ability and attitude, such as through the arrangement of the video, and set the viewing time, in which to answer and finally answer the question;, To require students to complete within a certain period of time; set the discussion topic, observe the degree of participation of students, so through a variety of ways to establish a student learning process evaluation system. This is also in line with engineering education certification requirements in the process of assessment requirements.

\section{Realization of Network Teaching}

The most important question of the application of online education is how to effectively achieve[2], some teachers will simply teach the network as a supplementary lesson to learn, the teachers still teach in accordance with the traditional teaching methods in class and ask students to learn to add online Content, homework after class, but the media change from paper to electronic documents. Some people completely change the present system, only to teach difficult and explain the operation, the overall knowledge content entirely depends on the students themselves to learn on the network, teachers only judge the degree of student learning through the operation .

Both methods have their own advantages and disadvantages[3] [4].So given the actual situation of our students' learning, I use a more compromise approach which classroom teaching is still retained ,but the teaching content has been greatly reduced on the network teaching practice of equipment of light chemical industry. There are enough the organization of the class on the net and fully ensure that students have enough learning resources, you can finish the course through self-learning. Through the choice of teaching contents, this part of the content, I will focus on reasoning, calculation and application, is still on the classroom to teach, and the knowledge, basic theoretical and expanding the content of reading is on the line, considering that the reason is that students' self-study ability is different. Based on the basic quality of our students, completely laissez-faire self-learning, there will be a considerable part of the students who can not achieve self-control, if there is only the offline learning, it will lost the meaning of online education .

In this course of the teaching model, a typical learning process should like this: In the classroom, he can make a systematic study on the knowledge points according to the syllabus, so as to master the knowledge of the course and establish the basic knowledge structure of the course. That is to say, he will know what the content belong to which parts of the world, according to their own situation to carry out in-depth study on one aspect, to achieve the basic learning requirements. He also should read the material on the internet, watch the video of teaching and complete the assignment. And $\mathrm{He}$ can test at the stage of study, if he has some knowledge not clear in the learning process, he can put it on the platform and answered by the teacher, while other students can answer, or initiate a discussion, everyone can participate in it(Students are very willing to participate, because the number of online and speak directly linked with the usual results). So it can achieve the interactive 
learning. The teacher can evaluate the students' learning process through the following aspects: firstly, Students participate in online activities, including his visits, online time, the number of questions raised, the number of responses, etc; secondly, quantity and quality of work; thirdly, the test scores; finally, quantity and quality of required learning tasks. Therefore, it can form a complete process evaluation system. The teacher's final exam is completely extracted from the network exercises library, students can self-evaluation. So students can improve their academic record, and ultimately improve their engineering ability.

\section{The Improvement of Network Teaching}

The Advantages of Network Teaching. Online teaching is undoubtedly the direction of information society progress, it has a fast, low cost and broad audience advantages, in the past decade, it had further absorbed the advantages of mobile networks, so that students could take full advantage of fragmented time, easy to carry Carrying electronic devices (mobile phones and tablet PCs), as well as computers and other means of learning anytime, anywhere, which should be the biggest advantage to attract students [5] [6].

In addition, the traditional way of learning is no longer limited to the text on the books, students need more media way, all-round acceptance of new knowledge, modern students is the most acceptable and interested in a lot of animation, video knowledge material, many students are able to find their own interests from these interactive learning in order to get the initiative to obtain knowledge of satisfaction and sense of accomplishment so as to develop their own inner ability to truly achieve our teaching objectives [7 ].

Network Teaching Shortcomings and Improvements. For equipment of light chemical industry professional courses of network teaching, it is a new thing, there are still shortcomings.

First of all, for institutions of higher learning, teaching is one aspect and educating people is equally important. How to realize the education of students in the network teaching, especially in the framework of the engineering education based on the Washington Agreement, the cultivation of students' Humanities and Social Sciences, social responsibility and professional ethics. Many examples prove that words and deeds are still the most direct and effective means, it is the most responsible way for students to the classroom's face-to-face, earnestly teach, directly reflects the role of teachers in education, and network teaching is no face to face, heart to heart communication form of corners, how to achieve moral education? This is a short board that network teaching can not be ignored. Therefore, achieving complete network teaching is not feasible, can be combined with the traditional teaching methods, complement each other is a more feasible approach.

\section{Summary}

Network teaching can fundamentally change the form of teaching so that it can show up teaching diversity and improve students' interest in learning, because of the combination with the network society, it can absorb the latest scientific and technological knowledge and improve the timeliness of professional knowledge, but it requires teachers with high information selection and processing capacity.

Network teaching requires that students have a higher learning self-control and strong learning initiative, teachers must have better control, especially for low-grade learning is not applicable.

The network teaching should be combined with the reality teaching to improve the students' humanistic quality education of capabilities.

\section{Acknowledgements}

This work was financially supported by the key projects of teaching reform in Qingdao University of Science and Technology. 


\section{References}

[1] H.Zhang: Higher Education of Chemical Engineering, Vol.28 (2011) No1, p.89-91(In Chinese)

[2] J.Q. Wu, C.L. Zhao and X. Xu: Chinese audio-visual education, (2000)No6,p.12-13(In Chinese)

[3] H.Zhang: Hubei paper, (2010) No1,p.44-46(In Chinese)

[4] X.B. Han, W.S. Ge, Q. Zhou, et al: Chinese audio-visual education, (2014)No1, p.61-68(In Chinese)

[5] F. Gao: open education research, Vol.18 (2012)No1, p.106-113(In Chinese)

[6] L.G. Zhang and X.L. Liu: E-education research, (2010)No12, p.36-41(In Chinese)

[7] H. Zhang, H.X. Lan, S.L. Wang, et al: Tianjin paper, Vol.37 (2015)No3,p.29-34(In Chinese)

[8] The Ministry of education. Some opinions on strengthening the teaching of the course of higher education to improve the quality of Teaching [R]. Higher Education (2001) No. 4(In Chinese)

[9] L. Zheng; L. Li; X.P. Yu: computer education, (2006) No.2, p.12 (In Chinese)

[10] Lu Ping, Dong Yuping: Journal of Shandong University of Technology (SOCIAL SCIENCE EDITION), (1997) No.4 p.95 (In Chinese) 